\title{
$\Delta 6$-fatty acid desaturase and fatty acid elongase mRNA expression, phagocytic activity and weight-to-length relationships in channel catfish (Ictalurus punctatus) fed alternative diets with soy oil and a probiotic
}

\author{
A. Santerre ${ }^{1}$, M.C. Téllez-Bañuelos ${ }^{1}$, J. Casas-Solís ${ }^{1}$, P. Castro-Félix ${ }^{1}$, \\ M.R. Huízar-López ${ }^{1}$, G.P. Zaitseva ${ }^{1}$, J.L. Horta-Fernández ${ }^{2}$, \\ E.A. Trujillo-García ${ }^{1}$, D. de la Mora-Sherer ${ }^{1}$, J.A. Palafox-Luna ${ }^{1}$ \\ and E. Juárez-Carrillo ${ }^{2}$ \\ ${ }^{1}$ Departamento de Biología Celular y Molecular, \\ Universidad de Guadalajara, Zapopan, Jalisco, México \\ ${ }^{2}$ Departamento de Ecología, \\ Centro Universitario de Ciencias Biológicas y Agropecuarias, \\ Universidad de Guadalajara, Zapopan, Jalisco, México \\ Corresponding author: M.C. Téllez-Bañuelos \\ E-mail: ceciliat@prodigy.net.mx \\ Genet. Mol. Res. 14 (3): 11222-11234 (2015) \\ Received January 29, 2015 \\ Accepted May 25, 2015 \\ Published September 22, 2015 \\ DOI http://dx.doi.org/10.4238/2015.September.22.16
}

\begin{abstract}
A time-course feeding trial was conducted for 120 days on juvenile channel catfish (Ictalurus punctatus) to study the effects of diets differing in oil source (fish oil or soy oil) and supplementation with a commercial probiotic. Relative levels of $\Delta 6$-fatty acid desaturase $(\triangle 6-F A D)$ and fatty acid elongase (FAE) expression were assessed in brain and liver tissues. Both genes showed similar expression levels in all groups studied. Fish weight-to-length relationships were evaluated using polynomial regression analyses, which identified a burst in
\end{abstract}


weight and length in the channel catfish on day 105 of treatment; this increase was related to an increase in gene expression. Mid-intestinal lactic acid bacterium (LAB) count was determined according to morphological and biochemical criteria using API strips. There was no indication that intestinal LAB count was affected by the modified diets. The Cunningham glass adherence method was applied to evaluate phagocytic cell activity in peripheral blood. Reactive oxygen species (ROS) generation was assessed through the respiratory burst activity of spleen macrophages by the NBT reduction test. Probiotic-supplemented diets provided a good substrate for innate immune system function; the phagocytic index was significantly enhanced in fish fed soy oil and the probiotic, and at the end of the experimental period, ROS production increased in fish fed soy oil. The substitution of fish oil by soy oil is recommended for food formulation and will contribute to promoting sustainable aquaculture. Probiotics are also recommended for channel catfish farming as they may act as immunonutrients.

Key words: Ictalurus punctatus; Probiotics; $\Delta 6$-fatty acid desaturase; Soy oil; Fatty acid elongase; Phagocytic activity

\section{INTRODUCTION}

The catfish genus Ictalurus is native to running water ecosystems of temperate areas of North America, ranging from the south of Canada to northern Mexico. More than 39 species of Ictalurus have been identified, although catfish farming is largely restricted to Ictalurus punctatus (channel catfish). The success of channel catfish farming is related to the improvements in overall management, disease control, and diet formulation. Fish oil (FO) obtained from natural resources has been used for decades in fish feed. This is no longer sustainable as FO has become scarce and expensive, and will constrain the future growth of aquaculture (Pike, 2005; Naylor et al., 2009; Bostock et al., 2010; Zhou et al., 2010). Vegetable oils, such as soy oil, are good candidates as alternative sources of oil for fish food formulation, and may help reduce the dependence of the aquaculture industry on FO. However, it is possible that the oil source used to prepare fish food may affect fatty acid (FA) metabolism in the fish. In particular, FO is rich in highly unsaturated fatty acids (HUFAs), while vegetable oils are rich in polyunsaturated fatty acids (PUFAs) (Bell et al., 2002). Fresh water fish are mostly incapable of de novo synthesis of HUFAs although they can convert PUFAs to HUFAs to a greater or lesser extent depending on the species (Sargent et al., 2002; Zheng et al., 2004a). $\Delta 6$ fatty acid desaturase ( $\triangle 6$-FAD) and fatty acid elongase (FAE) are critical enzymes in the HUFA biosynthetic pathway (Chen et al., 2014). High levels of HUFAs in fish food may inhibit the expression of $\triangle 6$-FAD and FAE, so total removal of FO from the diet may modulate the expression of these genes (Vagner and Santigosa, 2011).

Improvement of disease control in fish farms has included the prophylactic application of probiotics, which are inexpensive and easily accessible, present few side effects, and may produce substances that inhibit colonization by pathogenic microbes (El-Haroun, 2007; Soccol et al., 2010; Cui et al., 2013). Much of the research on alternative oil sources for fish food and food supplementation has dealt with their potential effects on digestion and growth 
parameters; however, modification of the diet may also modulate the immune function of the fish and their resistance to pathogens (Pirarat et al., 2011). In fish, phagocytosis is the main nonspecific cellular immune mechanism for destroying extracellular bacteria, viruses, and fungi in the environment. Phagocytic activity is followed by the generation of a series of reactive oxygen species (ROS) in a process called a respiratory burst, recognized as one of the key killing responses of phagocytes during microbial infection (Kokou et al., 2012).

In the present study, we investigated the effect of an alternative diet based on soy oil as the sole source of FAs, and of dietary supplementation with a commercial probiotic. We assessed the consequences of the dietary modifications using a range of parameters including $\triangle 6-F A D$ and FAE gene expression at the transcriptional level, growth in weight and length of the fish, gut lactic acid bacterium (LAB) content, phagocytic index, and ROS production in juvenile channel catfish maintained under controlled experimental conditions.

\section{MATERIAL AND METHODS}

\section{Experimental fish}

Juvenile channel catfish (I. punctatus) weighing $1.0 \pm 0.2 \mathrm{~g}$ were obtained from the Aquamol fish farm in Jamay, Jalisco, Mexico. Phenotypic males were used for all experiments. Fish were transferred to $400-\mathrm{L}$ fiberglass tanks containing a chlorine-free fresh water recirculating aquaculture system and were acclimated to greenhouse conditions for 1 month before the start of the trial. During this acclimation period, they were fed a standard $1.5-\mathrm{mm}$ feed size starter commercial diet (52\% crude protein; El Pedregal, Toluca, Mexico).

\section{Experimental design}

After the acclimation period, the juvenile fish $(6.83 \pm 0.15 \mathrm{~g})$ were randomly assigned to 12 aquariums ( 3 aquariums per diet) with individual water flow of $0.5 \mathrm{~L} / \mathrm{min}$. Each tank (30 x $45 \times 60 \mathrm{~cm}$ ) contained 25 fish at the beginning of the experiment. Fish were fed twice daily to apparent satiation. Water temperature was maintained at $27^{\circ} \pm 1^{\circ} \mathrm{C}$ and the physicochemical parameters of the culture system were maintained within the optimal ranges for the species (Robinson and $\mathrm{Li}, 2007$ ). The fish were routinely checked for signs of abnormal behavior and visible lesions. They were not vaccinated, and no antibiotics were used.

\section{Diets}

During the experiment the fish were fed commercial diets manufactured by Consorcio Super (Jalisco, Mexico). Diets were prepared according to the nutritional requirements of channel catfish (Robinson and $\mathrm{Li}, 2007$ ), and formulated with the same ingredients (35\% crude protein, attractants, minerals, and vitamins) except for the oil composition. Table 1 highlights the differences between the diets. The control diet (C diet) contained 2\% FO and 6\% soy oil. The alternative diet (S diet) contained 8\% soy oil and no FO. The CP and SP diets correspond to the $\mathrm{C}$ and $\mathrm{S}$ diets but were supplemented with the multispecies Bacterol-shrimp Forte probiotic after diet manufacture. This probiotic is derived from 14 different microorganisms including Bacillus, Lactobacillus, and Saccharomyces at an overall concentration of $5 \times 10^{8}$ 
colony-forming units (CFU/g (Farmacología en Aquacultura Veterinaria, Santiago, Chile). The probiotic was added at $1 \mathrm{~g} / \mathrm{kg}$ as recommended for other probiotics (Chang and Liu, 2002; Abdelhamid et al., 2009).

Table 1. Formulations of the four diets used to feed channel catfish for 120 days.

\begin{tabular}{|c|c|c|c|c|}
\hline & \multicolumn{4}{|c|}{ Diet } \\
\hline & $\mathrm{C}$ & $\mathrm{CP}$ & S & SP \\
\hline Fish oil (\%) & $2 \%$ & $2 \%$ & $0 \%$ & $0 \%$ \\
\hline Soy oil (\%) & $6 \%$ & $6 \%$ & $8 \%$ & $8 \%$ \\
\hline Probiotic & - & + & - & + \\
\hline
\end{tabular}

$\mathrm{C}=$ control diet $\mathrm{CP}=$ control diet supplemented with probiotic; $\mathrm{S}=$ soy-oil diet; $\mathrm{SP}=$ soy-oil diet supplemented with probiotic ( $1 \mathrm{~g} / \mathrm{kg}$ ) (- indicates no supplementation, + indicates supplementation).

\section{Sampling}

The experiment was run for 120 days. Every 2 weeks, three fish from each diet (one fish per aquarium) were randomly withdrawn and anesthetized with clove oil (100 mg/L). The fish were blotted dry, weighed, and measured (standard length). Peripheral blood was immediately withdrawn by caudal venipuncture with a 3-mL plastic syringe for the phagocytic assay; the remaining blood was passed into Eppendorf tubes and allowed to clot for $30 \mathrm{~min}$. Serum for opsonization was obtained by centrifugation at $200 \mathrm{~g}$ (Spectrofuge $24 \mathrm{D}$, Labnet, USA) for 20 min and was kept at $-20^{\circ} \mathrm{C}$ until needed. Once blood was withdrawn, fish were aseptically and rapidly dissected in order to obtain the liver, brain, and mid-intestine. At the end of the experimental period, the spleen was also obtained. These samples were evaluated as a pool (one pool per diet).

\section{Expression of fatty acid desaturase and fatty acid elongase mRNA in liver and brain}

Semi-quantitative reverse-transcription polymerase chain reaction (semi-quantitative RT-PCR) was used to evaluate the expression of $\triangle 6-F A D$ and FAE. Total RNA was extracted from $50 \mathrm{mg}$ tissue (liver and brain) using $1 \mathrm{~mL}$ Trizol reagent. Complementary DNA (cDNA) was synthesized from $500 \mathrm{ng}$ total RNA using oligo $\mathrm{dT}_{12-18}$ and M-MVL reverse-transcriptase (RT) following manufacturer protocols (Gibco-Invitrogen, USA). Quantity and integrity of the RNA was checked by UV spectrophotometry and agarose gel electrophoresis before cDNA synthesis. Specific primers for $\triangle 6-F A D, F A E$, and $\beta$-actin amplicons were designed from mRNA sequences obtained from GenBank. All gene-specific primers for semi-quantitative RT-PCR detection are listed in Table 2. Primers were synthesized by Integrated DNA Technologies (IDT, USA). Amplification was carried out in $25-\mu \mathrm{L}$ reaction volumes containing $1 \mathrm{X}$ PCR buffer, 3 $\mathrm{mM} \mathrm{MgCl}, 0.4 \mathrm{mM}$ of each dNTP, $0.4 \mu \mathrm{M}$ of each primer, and $1 \mathrm{U}$ Taq polymerase (GibcoInvitrogen); cDNA and milliQ water volumes were added according to $\beta$-actin normalization. Duplicate amplifications were performed using a PTC-100 thermocycler (MJ Research, USA) as follows: $95^{\circ} \mathrm{C}$ for $2 \mathrm{~min} ; 32$ cycles of denaturation at $95^{\circ} \mathrm{C}$ for $45 \mathrm{~s}$, annealing at $52^{\circ} \mathrm{C}$ for 45 $\mathrm{s}$, and elongation at $72^{\circ} \mathrm{C}$ for $45 \mathrm{~s}$; and a final incubation at $72^{\circ} \mathrm{C}$ for $5 \mathrm{~min}$. PCR products were separated by electrophoresis on $1.5 \%$ agarose gels stained with ethidium bromide. Results were analyzed using the Kodak 1D Image Analysis Software, Version 3.5 (Eastman Kodak CO, USA). Values are reported as arbitrary units. 
Table 2. Primers used for the semi-quantitative RT-PCR analysis of the expression of $\Delta 6$-fatty acid desaturase $(\triangle 6-F A D)$ and fatty acid elongase $(F A E)$ genes in brain and liver of channel catfish.

\begin{tabular}{|c|c|c|c|c|}
\hline GenBank accession No. & $\begin{array}{l}\text { Primer positions on } \\
\text { gene (forward/reverse) }\end{array}$ & Primer sequence & $\begin{array}{l}\text { Hybridization } \\
\text { temperature }\left({ }^{\circ} \mathrm{C}\right)\end{array}$ & $\begin{array}{l}\text { Amplicon } \\
\text { size (bp) }\end{array}$ \\
\hline$\overline{\triangle 6-F A D(\mathrm{EF} 125211.1)}$ & $26-43 / 129-111$ & $\begin{array}{l}\text { 5'-GGTCATTAAGGACCCTGA-3' } \\
\text { 5'-GAAGTACTGGTGCTGATG-3' }\end{array}$ & 52 & 121 \\
\hline FAE (CK417097.1) & $141-159 / 283-265$ & $\begin{array}{l}\text { 5'-TGTCTGGTGGTTGATTTC-3' } \\
\text { 5'-CGTTGGTGATTACAGAGC-3' }\end{array}$ & 52 & 143 \\
\hline$\beta$-actin (DQ399027.1) & 291-309/491-473 & $\begin{array}{l}\text { 5'-TGCCTATTCCTCCTCTCT-3' } \\
\text { 5'-GTGTTGGCATACAGATCC-3' }^{\prime}\end{array}$ & 52 & 201 \\
\hline
\end{tabular}

\section{Weight-to-length relationship}

The relationship between standard length $(\mathrm{L}$, in $\mathrm{cm})$ and weight $(\mathrm{W}$, in $\mathrm{g})$ of channel catfish was investigated by applying a polynomial regression analysis as described by Bhujel (2008) for biological systems.

\section{LAB quantification in mid-intestine}

LABs were quantified in order to study the effect of diets on intestinal microflora. Classical microbiological protocols were applied (Ghosh et al., 2014). Briefly, the midintestine segments were weighed, washed with $9 \mathrm{~mL}$ MRS (de Man, Rogosa and Sharpe; Difco Laboratories, USA), the selective medium for LAB bacteria, cut into pieces and vortexed. Serial dilutions were made in MRS broth and a $250-\mu \mathrm{L}$ aliquot of each dilution was pipetted onto MRS agar and incubated at $37^{\circ} \mathrm{C}$ for $48 \mathrm{~h}$. A Quebec counter was used to count the CFU of LAB according to morphology. Then, the bacteria were identified according to their biochemical criteria using API50CHL strips following manufacturer instructions (Biomerieux, France). All cultures were performed in duplicate for each intestinal sample. Data are reported as $\log$ of the number of CFU/g intestine, and as means $\pm \mathrm{SD}$.

\section{Phagocytic activity of peripheral blood evaluated by the glass adherence method}

Phagocytic cells from peripheral blood were used for the functional phagocytic assay. This was performed by a modification of the Cunningham glass adherence method reported by Casas-Solis et al. (2007); in our modified protocol, the antigen consisted of $1 \times 10^{6}$ CFU opsonized Aeromonas hydrophila (ATCC 7966, USA) (Giron-Perez et al., 2007). The phagocytic index is reported as the average number of $A$. hydrophila particles engulfed per cell, and was calculated by dividing the total number of engulfed particles by the cell count. All experiments were performed in duplicate for each experimental group.

\section{Respiratory burst activity (RBA) assay in spleen macrophages}

RBA produced by spleen macrophages was evaluated using the nitro-blue tetrazolium (NBT) reduction test (Tellez-Bañuelos et al., 2009). Briefly, a mixture of $100 \mu \mathrm{L}$ of spleen macrophages $\left(1 \times 10^{6}\right.$ cells $\left./ \mathrm{mL}\right)$ and $500 \mu \mathrm{L}$ PBS containing $0.1 \%$ NBT (Sigma, USA) and $25 \mathrm{x}$ $10^{6} \mathrm{CFU}$ opsonized A. hydrophila as the antigen (ATCC 7966, USA) was incubated at $25^{\circ} \mathrm{C}$ for $2 \mathrm{~h}$ with occasional shaking. The mixture was centrifuged at $1800 \mathrm{~g}$ for $5 \mathrm{~min}$. The reaction was 
stopped with $500 \mu \mathrm{L} 70 \%$ methanol and centrifuged at $1800 \mathrm{~g}$ for $5 \mathrm{~min}$. The cellular button was dried at $60^{\circ} \mathrm{C}$ for $15 \mathrm{~min}$, and $450 \mu \mathrm{L} 2 \mathrm{M}$ potassium hydroxide was added and the suspension was sonicated for $15 \mathrm{~min}$. Five hundred microliters of dimethyl sulfoxide (Sigma, USA) was added and the mixture was incubated for $10 \mathrm{~min}$, and then centrifuged at $4000 \mathrm{~g}$ for $5 \mathrm{~min}$. Optical density was measured with an OpsysMR microplate reader (Dynex Technologies, USA) at $630 \mathrm{~nm}$. The experiment was performed in triplicate.

\section{Statistical analysis}

Averaged data (means $\pm \mathrm{SD}$ ) are reported for each study group in a given experiment. Statistical analyses were carried out utilizing one-way ANOVA and the Tukey honestly significant difference post hoc test for all pairwise comparisons of the mean responses of the different experimental groups. In all cases, the significance level was set at $\mathrm{P}<0.05$.

\section{RESULTS}

\section{Semi-quantitative RT-PCR evaluation of $\triangle 6-F A D$ and $F A E$}

We performed semi-quantitative RT-PCR to measure the levels of expression of $\Delta 6$ FAD and FAE in liver and brain during the 120-day treatment period (Figure 1a). Single bands of the expected sizes were obtained (121 bp for $\triangle 6-F A D, 143 \mathrm{bp}$ for FAE, and $201 \mathrm{bp}$ for $\beta$-actin). No differences were observed between the four different diets at any sampling time (Figure $1 \mathrm{~b} ; \mathrm{P}>0.05$ ).

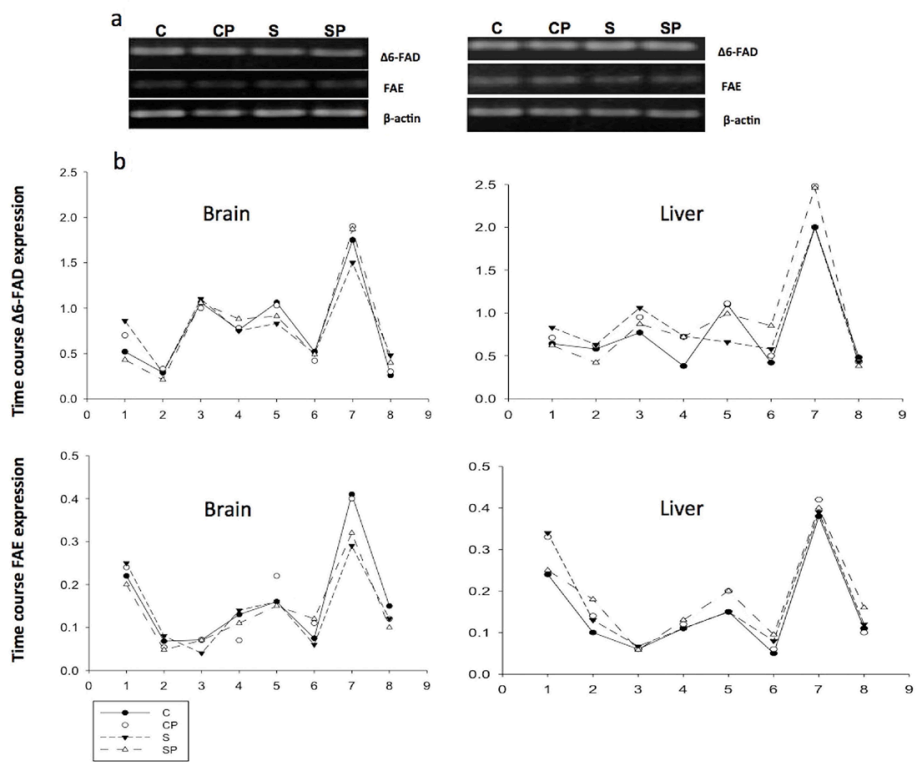

Figure 1. Expression of $\triangle 6$-fatty acid desaturase $(\triangle 6-F A D)$ and fatty acid elongase $(F A E)$ genes. a. RT-PCR products of brain and liver tissue from fish in each treatment group. b. Time-course changes in relative levels of $\triangle 6-F A D$ and $F A E$ mRNAs at 2-week intervals during the 120-day experiment ( 8 samples) in the brain and liver of channel catfish in the four diet groups (C, CP, S, and SP). Results are reported as means $\pm \mathrm{SD}$. For diet abbreviations, see legend to Table 1. 
For all four diets and at any sampling time, $\triangle 6-F A D$ expression was approximately four times higher than $F A E$ expression in both liver and brain. A significant increase $(\mathrm{P}<0.05)$ in the expression of the genes was seen in both tissues and in all dietary groups at day 105 of treatment (Figure 1b).

\section{Weight-to-length relationship}

The relationship between weight $(\mathrm{W}, \mathrm{g})$ and standard length $(\mathrm{L}, \mathrm{cm})$ of the channel catfish is shown in Figure 2. A polynomial regression analysis $\mathrm{W}=43.720-\left(12.406^{*} \mathrm{~L}\right)+$ $\left(1.072 * L^{2}\right)-\left(0.0123 * L^{3}\right), N=126$, indicated an $r$ value of 0.992 . No differences were observed among the $r$ values of the four dietary groups when evaluated individually (data not shown).

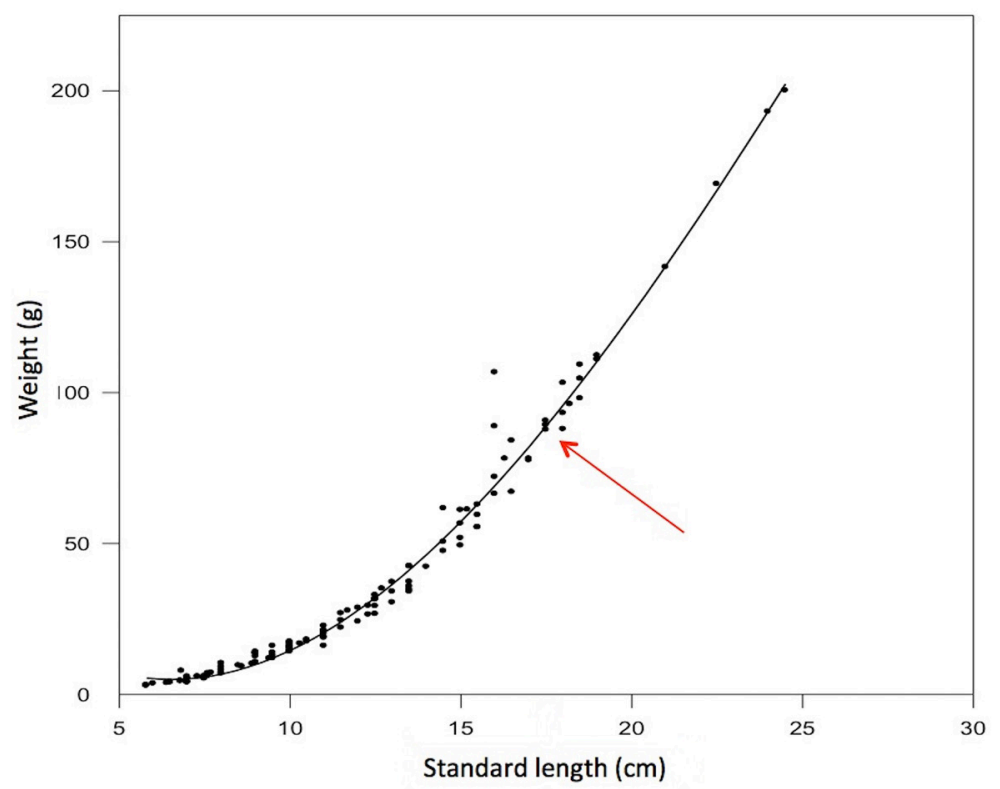

Figure 2. Relationship between weight $(\mathrm{g})$ and standard length $(\mathrm{cm})$ of channel catfish. A polynomial regression analysis was applied and the data were fitted to a regression curve. The arrow indicates the growth burst in the fish, which corresponds to a significant increase in transcriptional expression of $\triangle 6-F A D$ and $F A E$ genes.

\section{Intestinal $L A B$ content}

The LAB content values (log of the number of CFU/g mid-intestine) for the four diets were as follows: $6.87 \pm 0.42$ for the $\mathrm{C}$ diet; $6.95 \pm 0.39$ for the $\mathrm{CP}$ diet; $7.00 \pm 0.30$ for the $\mathrm{S}$ diet; and $6.95 \pm 0.33$ for the SP diet. Intestinal LAB count was not affected by either replacement of FO by soy oil or the supplementation of the diet with the probiotic.

\section{Phagocytic activity}

Our analysis of phagocytic activity in blood cells did not reveal any significant changes within each treatment group over the time course of the experiment; the data are 
therefore reported as means $\pm \mathrm{SD}$ for each treatment group (Figure 3). Fish that received the SP diet had a significantly higher phagocytic index $(13.3 \pm 1.98)$ than fish fed the control C $\operatorname{diet}(6.92 \pm 2.87)$ or the $\mathrm{CP} \operatorname{diet}(8.06 \pm 2.65)$. However, the phagocytic index of the SP group was not significantly different from that of the $\mathrm{S}$ group $(9.81 \pm 2.35)$.

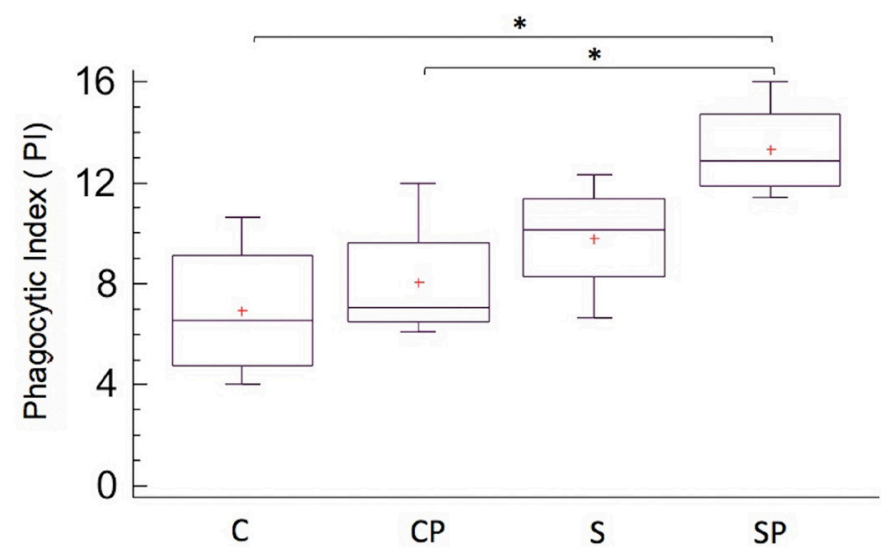

Figure 3. Box-plot representation of the effect of fish oil replacement and probiotic supplementation on the phagocytic index in channel catfish. The graphs show average behavior over the 120-day study. Results are reported as means $\pm \mathrm{SD}$; one-way ANOVA and the Tukey test were used for the analysis. The level of significance was set at $* \mathrm{P}<0.05$. For diet abbreviations, see legend to Table 1 .

\section{Respiratory burst activity}

RBA was evaluated on day 120 of the treatment period. A significant increase in RBA was found in the spleens of fish fed the $\mathrm{S}$ diet compared with fish fed the $\mathrm{C}$ diet (Figure 4). Moreover, RBA was significantly lower $(\mathrm{P}<0.05)$ in splenocytes from fish that received the probiotic (CP diet: $0.123 \pm 0.029$; SP diet: $0.281 \pm 0.008)$ compared to fish that did not receive this supplement (C diet: $0.392 \pm 0.023$; $\mathrm{S}$ diet: $0.503 \pm 0.012)$.

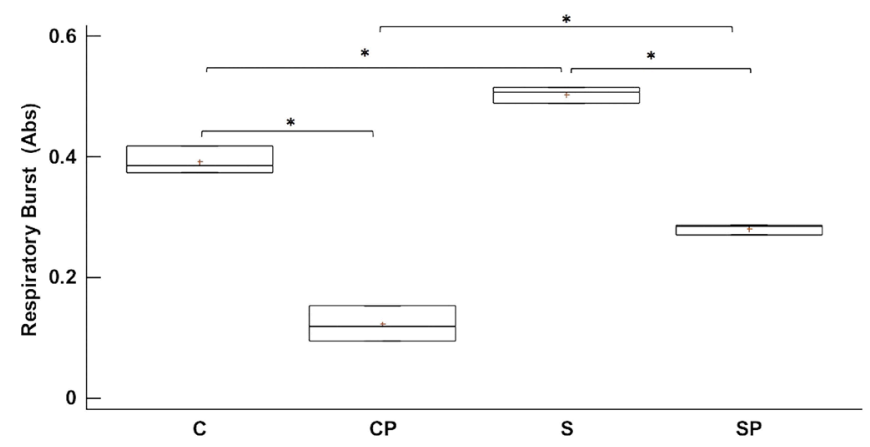

Figure 4. Box-plot representation of the effect of fish oil replacement and probiotic supplementation on respiratory burst activity in channel catfish at the end of the experiment. Catfish were fed four different diets (C, CP, S, and SP) for 120 days. Reactive oxygen species production in the splenocytes of the fish was determined using nitroblue tetrazolium reduction (absorbance at $630 \mathrm{~nm}$ ). Results are reported as means $\pm \mathrm{SD}$. One-way ANOVA and the Tukey test were used for the analysis. The level of significance was set at $* \mathrm{P}<0.05$. For diet abbreviations, see legend to Table 1 . 


\section{DISCUSSION}

Aquaculture is a fast-growing sector that provides many job opportunities and contributes to meeting the increasing demand of consumers for fishmeal. However, the successful development of this industry could stall as fish farming faces increasing production costs and the constant risk of fish diseases. The present 120-day study evaluated the effect of removing FO from the diet and of supplementing it with a commercial probiotic. Various endpoints were screened to assess the effects of dietary changes, namely, $\triangle 6-F A D$ and $F A E$ expression, growth in fish lengths and weights, intestinal LAB contents, and innate immune responses.

Juvenile channel catfish fed a diet without FO showed no significant differences in their weight-to-length ratio compared to fish fed the conventional diet. This indicates that dietary FO can be replaced by soy oil without compromising this growth parameter in channel catfish. A similar conclusion was reached in previous study of darkbarbel catfish (Pelteobagrus vachelli) that were fed diets with different amounts of soybean oil for 80 days (Jiang et al., 2013), and was also reported for other species such as Acanthopagrus schlegeli (Peng et al., 2008), Diplodus puntazzo (Piedecausa et al., 2007), Epinephelus malabaricus (Lin and Shiau, 2007), and Oncorhynchus mykiss (Caballero et al., 2002).

Probiotics have been proposed as alternative prophylactic agents for the aquaculture industry. Interestingly, another practical use of probiotics in fish diets is the promotion of growth by a variety of mechanisms including modulation of the immune system (Nayak, 2010). Sáenz de Rodriguez et al. (2009) and Garcia de la Banda et al. (2010) reported that growth and nutrient utilization were significantly higher in Senegalese sole receiving probiotics than in fish fed a control diet. However, Merrifield et al. $(2010,2011)$ conducted a 10 -week feeding trial to assess the effect of the probiotic Pediococcus acidilactici on rainbow trout and reported no significant improvement in growth performance or other parameters, such as feed utilization and carcass composition, in the probiotic-fed fish compared to the control group. Similarly, under our experimental conditions, the supplementation of channel catfish diets with a probiotic did not affect the weight-to-length ratios during the experimental period. A detailed study of additional growth parameters and a proximate analysis of channel catfish fed the commercial probiotic used here will be necessary before drawing final conclusions on its effect.

The extent to which fish transform PUFAs to HUFAs varies with the species (Sargent et al., 2002; Zheng et al., 2004a). Freshwater species such as carp, tilapia, trout, and salmonoids have a recognized ability to bio-convert PUFAs to HUFAs and this is related to the expression of $\triangle 6-F A D$ and FAE (Bell et al., 2002). The elimination of HUFAs from the diet of these species up-regulates the rate of transcription of $\triangle 6-F A D$ (mRNA). However, fish fed diets with a low HUFA content do not always show significant differences in $\triangle 6-F A D$ mRNA levels compared to fish fed diets rich in HUFAs (Vagner and Santigosa, 2011). To the best of our knowledge, the present study is the first report on the transcriptional expression of $\triangle 6-F A D$ and $F A E$ in channel catfish. Our data showed no statistical differences in the levels of $\triangle 6$ $F A D$ and $F A E$ mRNAs in the different treatment groups. The lack of a significant effect on expression of the $\triangle 6-F A D$ and $F A E$ genes in channel catfish under the $\mathrm{C}$ and $\mathrm{S}$ diet may be due to the low percentage of FO in the control diet used here (C diet).

Over the time-course of the study, the levels of expression of $\triangle 6-F A D$ and $F A E$ followed the same patterns in liver and brain; in both tissues, a significant increase in expression of the genes was observed on day 105 of treatment. This increase coincided with a burst in weight and length and might represent a response to the need of the fish for synthesis, storage, and 
distribution of FA to different parts of the body for various physiological functions (Kandemir and Polat, 2007). The relative expression of $\triangle 6-F A D$ was four times higher than that of FAE; a similar result has been reported in salmon (Zheng et al., 2004b). The supplementation of the diets with a probiotic did not affect $\triangle 6-F A D$ or $F A E$ gene expression.

Lactic acid bacteria are amongst the most widely used probiotics. They are good producers of bacteriocins and organic acids; these compounds have inhibitory effects on the growth of some pathogens in fish and give $\mathrm{LAB}$ a competitive advantage over other bacteria (Zhou et al., 2010; Lara-Flores, 2011). Our experimental data showed no statistical differences in LAB count between treatment groups, a finding that is consistent with previous studies in which differences in the intestinal microbial balance only occurred in a few experimental cases (Vine et al., 2004; Varela et al., 2010). In agreement with other authors (Welker and Lim, 2011), we suggest that the LAB present in the probiotic had not settled on the intestinal mucous membrane of channel catfish because of the constant washing of this organ within the natural environment of the fish. It is possible that the effect of the probiotic on growth parameters may be long-term; this is an important consideration for practical application of probiotics in fish farms.

Even if the removal of FO and the supplementation of the diet with a probiotic did not have a significant effect on the measured parameters, they did provide a boost to the innate immune function. Comparison of the phagocytic indexes of fish fed on $\mathrm{C}$ or $\mathrm{S}$ diets showed that the use of soy oil as the sole source of FA increased phagocytic function in channel catfish. Montero et al. (2003) reported a significantly higher phagocytic activity in gilthead seabream (Sparus aurata) fed a diet with FO compared to a diet of $80 \%$ soybean oil for prolonged periods. In contrast, our data suggest that freshwater, omnivorous fish species such as channel catfish are better suited to total FO replacement than marine fish. Another interesting observation was that supplementation of the $\mathrm{S}$ diet with a probiotic enhanced the positive effect of the S diet on the phagocytic index. This index also increased in the CP diet compared with the $\mathrm{C}$ diet, but the difference was not significant. These results are consistent with other reports showing that probiotics stimulate phagocytosis in different fish species (Nayak, 2010; Soccol et al., 2010; Sun et al., 2010). Thus, the SP diet has potential utility in aquaculture of channel catfish as it enhances the defense mechanisms of this species against pathogenic organisms.

The production of ROS was evaluated at day 120 of the experimental period. RBA significantly increased in splenocytes of fish fed with the $\mathrm{S}$ diet compared to those on the $\mathrm{C}$ diet. This finding differs from that in the study of Montero et al. (2003) in which Sparus aurata were fed a diet of $80 \%$ soybean oil for 204 days. Vegetable oil had no effect on macrophage RBA in this species compared to fish fed a standard diet. The contrasting outcomes in these two studies may be related to differences in species and treatment duration. The present study also showed that supplementation of the $\mathrm{C}$ and $\mathrm{S}$ diets with a probiotic significantly decreased ROS values on day 120 . ROS are products of the phagocytic process and are highly microbicidal, but when produced in excess they can lead to severe cellular damage (TellezBañuelos et al., 2009). One of the main enzymes that detoxify ROS is superoxide dismutase (SOD), which is abundant in fish tissue (Harikrishnan et al., 2011). In Epinephelus coioides given a supplement including Saccharomyces cerevisiae, Chiu et al. (2010) reported that SOD activity increased on day 28 of treatment. Furthermore, Sun et al. (2010) showed in the same species that Bacillus pumilus and Bacillus clausii provoked an increase in SOD concentration on day 60. From the results of the present study, we hypothesize that the decrease in ROS seen 
in fish fed diets supplemented with a probiotic might be due to its long-term effect on SOD activity in fish immune cells. Complementary time-course data will be needed to substantiate this hypothesis.

In conclusion, no effects on weight-to-length relationships or transcriptional expression of $\triangle 6-F A D$ or FAE were found in channel catfish fed for 120 days on a diet based on soy oil as the sole source of FA or a diet supplemented with a commercial probiotic. The results presented here indicate that channel catfish might easily be transferred from a commercial diet including fish oil to a diet based on soy oil as a source of FA without compromising their growth, but still maintaining their health. This is encouraging for catfish farming as the largescale removal of FO from catfish meal would help to lower fish food cost. In addition, it would contribute to the sustainability of aquaculture and help to preserve the balance of the marine ecosystem. Our results also indicate that the use of probiotics is beneficial to channel catfish farming. The probiotic used here acted as an immunonutrient by enhancing immunity in the catfish. Its long-term use may reduce the incidence of infectious fish disease and improve the overall health of channel catfish in aquaculture. Ongoing experiments will allow us to characterize classical growth parameters and FA content in order to give a more thorough assessment of growth performance.

\section{ACKNOWLEDGMENTS}

Research financed by the Consejo Estatal de Ciencia y Tecnología de Jalisco (COECYTJAL), México (research grant \#25-2008-609), by the P3E-University of Guadalajara, and by the PROMEP-SEP (CA-482 y CA-582) Research Programs, México. We wish to acknowledge MSc Miguel Enrique Magaña Virgen for his excellent technical assistance with artwork.

\section{REFERENCES}

Abdelhamid AM, Mehrim AI, El-Barbary MI, Ibrahim SM, et al. (2009). Evaluation of a new Egyptian probiotic by African catfish fingerlings. J. Environ. Sci. Technol. 2: 133-145.

Bell JG, Henderson RJ, Tocher DR, McGhee F, et al. (2002). Substituting fish oil with crude palm oil in the diet of Atlantic salmon (Salmo salar) affects tissue fatty acid composition and hepatic fatty acid metabolism. J. Nutr. 132: 222-230.

Bhujel RC (2008). Statistics for aquaculture. 1st edn. Wiley-Blackwell, Ames.

Bostock J, McAndrew B, Richards R, Jauncey K, et al. (2010). Aquaculture: global status and trends. Philos. Trans. R. Soc. B 365: 2897-2912.

Caballero MJ, Obach A, Rosenlund G, Montero D, et al. (2002). Impact of different dietary lipid sources on growth, lipid digestibility, tissue fatty acid composition and histology of rainbow trout, Oncorhynchus mykiss. Aquaculture 214: 253-271.

Casas-Solis J, Santerre A, Giron-Perez MI, Reynoso-Orozco R, et al. (2007). A comparative study of phagocytic activity and lymphoproliferative response in five varieties of tilapia Oreochromis spp. J. Fish Biol. 71: 1541-1545.

Chang CI and Liu WY (2002). An evaluation of two probiotic bacterial strains, Enterococcus faecium SF68 and Bacillus toyoi, for reducing edwardsiellosis in cultured European eel, Anguilla anguilla L. J. Fish Dis. 25: 311-315.

Chen QM, Cheng DJ, Liu SP, Ma ZG, et al. (2014). Genome-wide identification and expression profiling of the fatty acid desaturase gene family in silkworm, Bombyx mori. Genet. Mol. Res.13: 3747-3760.

Chiu CH, Cheng CH, Gua WR, Guu YK, et al. (2010). Dietary administration of the probiotic, Saccharomyces cerevisiae P13, enhanced the growth, innate immune responses, and disease resistance of the grouper, Epinephelus coioides. Fish Shellfish Immunol. 29: 1053-1059.

Cui C, Shen CJ, Jia G and Wang KN (2013). Effect of dietary Bacillus subtilis on proportion of Bacteroidetes and Firmicutes in swine intestine and lipid metabolism. Genet. Mol. Res. 12: 1766-1776. 
El-Haroun ER (2007). Improved growth rate and feed utilization in farmed African catfish Clarias gariepinus (Burchell 1822) through a growth promoter Biogen ${ }^{\circledR}$ Supplementation. J. Fish. Aquatic Sci. 2: 319-327.

Garcia de la Banda I, Lobo C, Leon-Rubio JM, Tapia-Paniagua S, et al. (2010). Influence of two closely related probiotics on juvenile Senegalese sole (Solea senegalensis, Kaup 1858) performance and protection against Photobacterium damselae subsp. piscicida. Aquaculture 306: 281-288.

Giron-Perez MI, Santerre A, Gonzalez-Jaime F, Casas-Solis J, et al. (2007). Immunotoxicity and hepatic function evaluation in Nile tilapia Oreochromis niloticus exposed to diazinon. Fish Shellfish Immunol. 23: 760-769.

Ghosh S, RingØ E, Gnana Selvam AD, Mujeeb Rahiman KM, et al. (2014). Gut associated lactic acid bacteria isolated from the estuarine fish Mugil cephalus: molecular diversity and antibacterial activities against pathogens. Int. J. Aquac. 4: 1-11.

Harikrishnan R, Kim MC, Kim JS, Balasundaram C, et al. (2011). Immunomodulatory effect of probiotics enriched diets on Uronema marinum infected olive flounder. Fish Shellfish Immunol. 30: 964-971.

Jiang X, Chen L, Qin J, Qin C, et al. (2013). Effects of dietary soybean oil inclusion to replace fish oil on growth, muscle fatty acid composition, and immune responses of juvenile darkbarbel catfish, Pelteobagrus vachelli. Afr. J. Agric. Res. 8: 1492-1499.

Kandemir S and Polat N (2007). Seasonal variation of total lipid and total fatty acid in muscle and liver of rainbow trout (Oncorhynchus mykiss W., 1792) reared in Derbent Dam Lake. Turkish J. Fish. Aquatic Sci. 7: 27-31.

Kokou F, Rigos G, Henry M, Kentouri M, et al. (2012). Growth performance, feed utilization and non-specific immune response of gilthead sea bream (Sparus aurata L.) fed graded levels of a bioprocessed soybean meal. Aquaculture 364-365: 74-81.

Lara-Flores M (2011). The use of probiotic in aquaculture: an overview. Int. Res. J. Microbiol. 2: 471-478.

Lin YH and Shiau SY (2007). Effects of dietary blend of fish oil with corn oil on growth and non-specific immune responses of grouper, Epinephelus malabaricus. Aquac. Nutr. 13: 137-144.

Merrifield DL, Dimitroglou A, Bradley G, Baker RTM, et al. (2010). Probiotic applications for rainbow trout (Oncorhynchus mykiss Walbaum) I. Effects on growth performance, feed utilization, intestinal microbiota and related health criteria. Aquac. Nutr. 16: 504-510.

Merrifield DL, Bradley G, Harper GM, Baker RTM, et al. (2011). Assessment of the effects of vegetative and lyophilized Pediococcus acidilactici on growth, feed utilization, intestinal colonization and health parameters of rainbow trout (Oncorhynchus mykiss Walbaum). Aquac. Nutr. 17: 73-79.

Montero D, Kalinowski T, Obach A, Robaina L, et al. (2003). Vegetable lipid sources for gilthead seabream (Sparus aurata): effects on fish health. Aquaculture 225: 353-370.

Nayak SK (2010). Probiotics and immunity: a fish perspective. Fish Shellfish Immunol. 29: 2-14.

Naylor RA, Hardy RW, Bureau DP, Chiu A, et al. (2009). Feeding aquaculture in an era of finite resources. Proc. Natl. Acad. Sci. U. S. A. 106: 15103-15110.

Peng SM, Chen LQ, Qin JG, Hou JL, et al. (2008). Effects of replacement of dietary fish oil by soybean oil on growth performance and liver biochemical composition in juvenile black seabream, Acanthopagrus schlegeli. Aquaculture 276: 154-161.

Piedecausa MA, Mazón MJ, García B, Hernández MD (2007). Effects of total replacement of fish oil by vegetable oils in the diets of sharpsnout seabream (Diplodus puntazzo). Aquaculture 26: 211-219.

Pike IH (2005). Eco-efficiency in aquaculture: global catch of wild fish used in aquaculture. Int. Aquafeed 8: 38-40.

Pirarat N, Pinpimai K, Endo M, Katagiri T, et al. (2011). Modulation of intestinal morphology and immunity in Nile tilapia (Oreochromis niloticus) by Lactobacillus rhamnosus GG. Res. Vet. Sci. 91: e92-e97.

Robinson EH and Li MH (2007). Catfish protein nutrition: revised. Bulletin 1153. Office of Agriculture Communications, Mississippi State University, Starkville.

Sáenz de Rodriguez MA, Diaz-Rosales P, Chabrillon M, Smidt H, et al. (2009). Effect of dietary administration of probiotics on growth and intestine functionality of juvenile Senegalese sole (Solea senegalensis, Kaup 1858). Aquac. Nutr. 15: 177-185.

Sargent JR, Tocher DR and Bell JG (2002). The lipids. Fish Nutr. 3: 181-257.

Soccol CR, Porto de Souza Vandenberghe L, Rigon Spier M, Pedroni Medeiros AB, et al. (2010). The potential of probiotics: a review. Food Technol. Biotechnol. 48: 413-434.

Sun YZ, Yang HL, Ma RL and Lin WY (2010). Probiotic applications of two dominant gut Bacillus strains with antagonistic activity improved the growth performance and immune responses of grouper Epinephelus coioides. Fish Shellfish Immunol. 29: 803-809.

Tellez-Bañuelos MC, Santerre A, Casas-Solis J, Bravo-Cuellar A, et al. (2009). Oxidative stress in macrophages from spleen of Nile tilapia (Oreochromis niloticus) exposed to sublethal concentration of endosulfan. Fish Shellfish Immunol. 27: 105-111. 
Vagner M and Santigosa E (2011). Characterization and modulation of gene expression and enzymatic activity of delta-6 desaturase in teleosts: a review. Aquaculture 315: 131-143.

Varela JL, Ruíz-Jarabo I, Vargas-Chacoff L, Arijo S, et al. (2010). Dietary administration of probiotic Pdp11 promotes growth and improves stress tolerance to high stocking density in gilthead seabream Sparus auratus. Aquaculture 309: 265-271.

Vine NG, Leukes WD, Kaiser H, Daya S, et al. (2004). Competition for attachment of aquaculture candidate probiotic and phatogenic bacteria on fish intestinal mucus. J. Fish Dis. 27: 319-326.

Welker TL and Lim C (2011). Use of probiotics in diets of tilapia. J. Aquac. Res. Development S1:014. Doi: 10.4172/21559546.S1-014.

Zheng X, Seiliez I, Hastings N, Tocher DR, et al. (2004a). Characterization and comparison of fatty acyl $\Delta 6$ desaturase cDNAs from freshwater and marine teleost fish species. Comp. Biochem. Physiol. Part B 139: 269-279.

Zheng X, Tocher DR, Dickson CA, Bell JG, et al. (2004b). Effects of diets containing vegetable oil on expression of genes involved in highly unsaturated fatty acid biosynthesis in liver of Atlantic salmon (Salmo salar). Aquaculture 236: 467-483.

Zhou X, Wang Y, Yao J and Li W (2010). Inhibition ability of probiotic, Lactococcus lactis, against A. hydrophila and study of its immunostimulatory effect in tilapia (Oreochromis niloticus). Int. J. Eng. Sci. Technol. 2: 73-80. 